\title{
Neurophysiological insights in dystonia and its response to deep brain stimulation treatment
}

\author{
Stephen Tisch ${ }^{1,2}$ (D) Patricia Limousin ${ }^{3}[$
}

Received: 2 February 2020 / Accepted: 11 May 2020 / Published online: 7 July 2020

(c) The Author(s) 2020

\begin{abstract}
Dystonia is a movement disorder characterised by involuntary muscle contractions resulting in abnormal movements, postures and tremor. The pathophysiology of dystonia is not fully understood but loss of neuronal inhibition, excessive sensorimotor plasticity and defective sensory processing are thought to contribute to network dysfunction underlying the disorder. Neurophysiology studies have been important in furthering our understanding of dystonia and have provided insights into the mechanism of effective dystonia treatment with pallidal deep brain stimulation. In this article we review neurophysiology studies in dystonia and its treatment with Deep Brain Stimulation, including Transcranial magnetic stimulation studies, studies of reflexes and sensory processing, and oscillatory activity recordings including local field potentials, micro-recordings, EEG and evoked potentials.
\end{abstract}

Keywords Dystonia $\cdot$ Neurophysiology $\cdot$ Gpi DBS

$\begin{array}{ll}\text { Abbreviations } \\ \text { DBS } & \text { Deep brain stimulation } \\ \text { EcoG } & \text { Electrocorticography } \\ \text { EMG } & \text { Electromyography } \\ \text { EEG } & \text { Electroencephalography } \\ \text { EP } & \text { Evoked potentials } \\ \text { GPe } & \text { Globus pallidus externus } \\ \text { GPi } & \text { Globus pallidus internus } \\ \text { LFP } & \text { Local field potentials } \\ \text { LTD } & \text { Long-term depression } \\ \text { LTP } & \text { Long-term potentiation } \\ \text { MEG } & \text { Magnetic encephalography } \\ \text { PAS } & \text { Paired associative stimulation }\end{array}$

Communicated by Sven Bestmann.

Patricia Limousin

p.limousin@ucl.ac.uk

Stephen Tisch

stisch@stvincents.com.au

1 School of Medicine, University of New South Wales, Sydney, Australia

2 Department of Neurology, St Vincent's Hospital, Sydney, Australia

3 Department of Clinical and Movement Neurosciences, UCL Queen Square Institute of Neurology, 33 Queen Square, 2nd floor, Box 146, London WC1N 3BG, UK

$\begin{array}{ll}\text { PD } & \text { Parkinson's disease } \\ \text { rTMS } & \text { Repetitive transcranial magnetic stimulation } \\ \text { SICI } & \text { Short latency intracortical inhibition } \\ \text { SSEPs } & \text { Somatosensory evoked potentials } \\ \text { STN } & \text { Subthalamic nucleus } \\ \text { TMS } & \text { Transcranial magnetic stimulation } \\ \text { Vc } & \text { Ventro-caudal nucleus of the thalamus } \\ \text { Vim } & \text { Ventro-intermediate nucleus of the thalamus } \\ \text { Voi } & \text { Ventral oral nucleus of the thalamus }\end{array}$

\section{Introduction}

Dystonia is defined by "sustained or intermittent muscle contractions that lead to abnormal movements, postures, or both" (Fahn 1988). The most recent consensus definition of dystonia includes tremor and highlights that dystonic movements are "typically patterned, twisting, and may be tremulous, initiated or worsened by voluntary action and associated with overflow muscle activation" (Albanese et al. 2013). There are many different types of dystonia and causes; the current classification system uses dual axis of clinical features such as age of onset, body distribution and underlying cause such as neuropathology or gene (Albanese et al. 2013).

Although the pathophysiology of dystonia is not fully understood, the loss of intracortical inhibition, increased 
cortical plasticity and abnormal sensorimotor integration are known to be involved in dystonia.

Deep brain stimulation of the globus pallidus interna (GPi-DBS) is considered effective and safe in refractory dystonia (Krauss et al. 1999; Coubes et al. 2000; Vidailhet et al. 2005; Kupsch et al. 2006; Volkmann et al. 2012, 2014). The time course of the effect is gradual but the mobile components tend to respond quickly and the tonic elements take longer (Chung and Huh 2016). In addition, different causes of dystonia can have different outcomes after DBS (Tisch 2018). GPi is the most commonly used target but some patients have also been implanted in the subthalamic nucleus (STN) and the thalamus.

DBS has also brought the opportunity to broaden research options in dystonia by allowing the record activity as well as measuring physiological changes in parallel to improvement. Here we review the neurophysiology of dystonia and its response to DBS.

\section{Transcranial magnetic stimulation (TMS)}

The development of TMS by Barker in 1985 (Barker et al. 1985 ) and its refinement as a viable tool for in vivo assessment of motor cortex and cortico-motor pathways (Rothwell 1991) heralded an important chapter in an improved pathophysiological understanding of dystonia. Concepts of decreased excitability of inhibitory circuits within the brain and spinal cord underlying dystonia, derived from studies of H-reflex reciprocal inhibition (Nakashima et al. 1989) and blink reflexes (Berardelli et al. 1985) led to initial TMS studies evaluating cortical excitability in dystonia. The first TMS study in dystonia was performed by Ridding and Rothwell in 1995 and compared focal hand dystonia patients with healthy subjects and showed reduced short latency intracortical inhibition (SICI) at rest, interpreted as evidence for decreased excitability within intracortical inhibitory circuits (Ridding et al. 1995). An additional important finding of this study was that defective cortical inhibition was present bilaterally despite dystonia being present only unilaterally, providing evidence of distributed pathophysiological abnormalities in brain regions unaffected by dystonia, a finding replicated in other studies leading to the important concept of endophenotypic abnormalities acting as a substrate upon which environmental factors may operate to produce dystonia (Meunier et al. 2001). Further TMS studies demonstrated that reduced intracortical inhibition was present not only at rest but also preceding (Gilio et al. 2003) and during voluntary movement in focal hand dystonia patients (Chen et al. 1997a, b; Stinear and Byblow 2004). Similar reductions in cortical inhibition were found in segmental and generalised forms of dystonia (Rona et al. 1998) and non-manifesting carriers of TOR1A/DYT1 (Edwards et al. 2006), further supporting the notion of abnormal endophenotypes in dystonia. Using TMS techniques it has been demonstrated that patients with musician's dystonia have greater reductions in SICI during hand muscle vibration stimuli than patients with writer's cramp suggesting sensory input playing a greater role in musician's dystonia (Rosenkranz et al. 2005). Collectively, TMS studies have provided evidence of reduced excitability of inhibitory circuits within the motor cortex providing further support for the loss of inhibition model of dystonia where action selection and topographic motor specificity are compromised leading to unwanted movements and co-contraction (Mink 1996; Hallet 2004).

TMS studies have also elucidated important interactions between pre-motor cortex and primary motor cortex in dystonia. In patients with writer's cramp, low-frequency inhibitory TMS over the premotor cortex results in prolongation of the primary motor cortex silent period reflecting reversal of abnormally reduced motor cortex inhibition and a corresponding improvement in handwriting performance (Murase et al. 2005). Abnormally increased inhibition of the primary motor cortex by the premotor cortex has been demonstrated in patients with writer's cramp at rest and during movement using a paired pulse TMS paradigm. In the same study, premotor cortex single pulse TMS preceding a manual choice reaction time task, reduced error rates without altering reaction time. The inhibition exerted by premotor cortex on primary motor cortex is likely supra-spinal as reflected in unchanged upper limb H-reflex amplitudes, and has been interpreted as compensatory in response to underlying disinhibition of the primary motor cortex in dystonia (Richardson et al. 2014).

A significant development in TMS studies for dystonia appeared with techniques allowing the elicitation of short-term cortical plasticity effects resembling long- term potentiation (LTP) and long-term depression (LTD). Lowfrequency rTMS (repetitive TMS) around $1 \mathrm{~Hz}$ leads to sustained decreases in motor cortex excitability (Chen et al. 1997a; Touge et al. 2001), higher frequency 5-25 Hz rTMS produces sustained increases in cortical excitability (Peinemann et al. 2004; Khedr et al. 2007), and pulsatile $50 \mathrm{~Hz}$ theta burst rTMS can efficiently induce either sustained increases or decreases in motor cortex excitability (Huang et al. 2005).

Motor cortex plasticity can also be generated using combined TMS and median nerve stimulation with $25 \mathrm{~ms}$ interval between stimuli, so called paired associative stimulation (PAS) which allows topographically restricted increase in motor cortex excitability that can be blocked by NMDA antagonists suggesting LTP-like mechanisms (Stefan et al. 2000, 2002). With shorter interstimulus intervals LTD like effects from PAS have also been demonstrated (Wolters et al. 2003). Patients with focal dystonia display increased motor cortex plasticity to TMS PAS with reduced cortico-motor 
topographic specificity (Quartarone et al. 2003; Weise et al. 2006), providing evidence that altered sensorimotor cortical plasticity may play an important role in dystonia. Motor cortex plasticity following TMS PAS is normal in patients with functional dystonia and increased in organic dystonia patients (Quartarone et al. 2009), whereas cortical and spinal disinhibition is equal in both conditions (Espay et al. 2006; Avanzino et al. 2008), suggesting that motor cortex plasticity changes may be a more fundamental feature of organic dystonia. The role of the cerebellum in modifying motor cortex plasticity in dystonia has been evaluated using TMS cerebellar cortex stimulation combined with PAS during hand-eye coordination task, which found that patients with writer's cramp have defective cerebellar inhibition of motor cortex plasticity (Hubsch et al. 2013). Increased brain plasticity in dystonia has also been demonstrated using TMS protocols other than PAS including low-frequency $1 \mathrm{~Hz}$ (Siebner et al. 2003; Baumer et al. 2007) and theta burst rTMS, where patients with cervical and segmental dystonia showed greater and longer lasting motor cortex inhibition than healthy subjects or non-manifesting TOR1A/DYT1 carriers (Edwards et al. 2006).

The emergence of GPi DBS stimulation as an effective treatment for dystonia (Krauss et al. 1999; Coubes et al. 2000; Vidailhet et al. 2005) generated interest as to the underlying physiological mechanisms of improvement in dystonia after GPi DBS (Tisch et al. 2007a) and provided new opportunities to assess dystonia pathophysiology. The Queen Square group, including Prof John Rothwell, was among the first to utilize TMS techniques to evaluate the physiological effects of GPi DBS in dystonia. The safety of TMS in patients with implanted DBS systems had been established in a previous study which evaluated TMS cortical excitability measures in patients with GPi DBS ON and OFF stimulation and demonstrated a reversible reduction in motor cortex excitability with GPi DBS OFF with no effects on intracortical inhibition (Kuhn et al 2003). The first study assessing effects of GPi DBS on motor cortex plasticity using TMS included ten patients with idiopathic isolated generalised dystonia, some TOR1A/DYT1 positive with stable significant improvement following effective GPi DBS evaluated using TMS PAS with DBS ON and OFF in separate sessions. With GPi DBS OFF patients showed similar degree of motor cortex plasticity to PAS as healthy controls; however, with DBS ON, excitatory motor cortex plasticity was abolished and shifted to cortical inhibition, which correlated with the degree of clinical improvement from DBS (Tisch et al. 2007b). The study provided evidence of reversal of abnormally excessive motor cortex plasticity as a possible mechanism of action of GPi DBS for dystonia (see Fig. 1). The same group went on to study longitudinal changes in motor cortex excitability and plasticity using TMS PAS in a cohort of dystonia patients before and

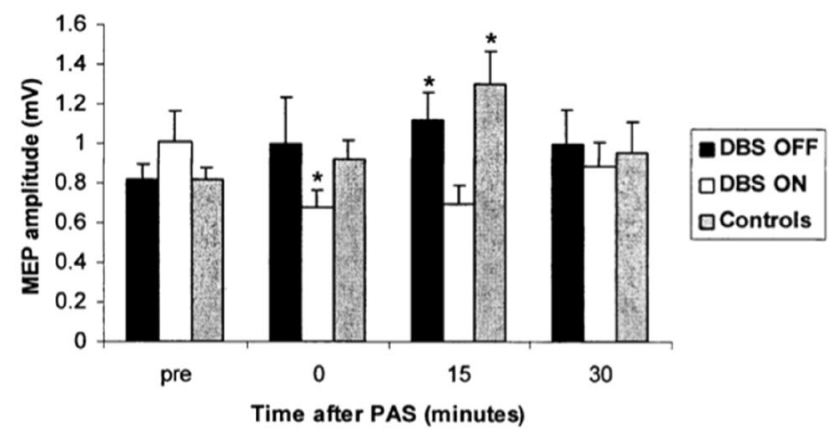

Fig. 1 Effect of PAS on resting MEP amplitude with GPi DBS ON and OFF in dystonia patients. Note that DBS ON abolishes excitatory post-PAS plasticity (decrease in MEP amplitude), whereas DBS OFF and control subjects show preserved PAS response

after DBS and found that SICI was reduced and plasticity increased in dystonia patients prior to DBS. One month after DBS, TMS PAS motor cortex plasticity was abolished but gradually increased towards normal levels at 3 and 6 months, while SICI improved gradually over the same time course mirroring progressive improvement in clinical symptoms (Ruge et al. 2011a). The progressive time-course of improvement in dystonia symptoms after GPi DBS is well described (Yianni et al. 2003; Vidailhet et al. 2005; Tisch et al. 2006a, b) and the finding of longitudinal changes in experimentally induced motor cortex plasticity suggests a potential mechanistic role. How might GPi DBS decrease excessive motor cortex plasticity in dystonia? It is known GPi DBS reduces ipsilateral excessive cortical activation in premotor and primary motor areas likely through enhanced thalamocortical inhibition (Kumar et al. 1999; Detante et al. 2004). A further mechanism may be increased background activity from GPi DBS, which may interfere with plasticity formation as demonstrated when anodal direct current stimulation is applied during PAS (Nitsche et al. 2007). Some further clues come from an interesting study, which evaluated the time-course of TMS PAS motor cortex plasticity in long-term GPi dystonia patients before and after switching off the DBS for 2 days (Ruge et al. 2011b). In keeping with previous studies PAS plasticity was almost absent and SICI was reduced with DBS ON. With DBS OFF for 2 days there was no change in SICI or plasticity at a group level, however there was a strong correlation between the amount of PAS plasticity ON DBS and the retention of clinical benefit after stopping DBS. These results suggest that many years of GPi DBS results in longterm changes in motor cortex plasticity underlying clinical benefit and that individual variation in plasticity profiles may dictate the extent to which clinical benefits persist.

In summary, TMS has delivered important insights in dystonia pathophysiology and mechanisms of action of GPi DBS and the contribution of Professor John Rothwell to this field of study merits special acknowledgement. 


\section{EMG, reflex studies and sensory processing in dystonia}

Traditional perspectives of dystonia as primarily due to abnormal basal ganglia activity have evolved to current the view of dystonia as a network disorder operating at all levels of the nervous system including cerebral cortex, thalamus, basal ganglia, cerebellum, brain stem and spinal cord (Tisch 2018). Important clinical hallmarks of dystonia including co-contraction and overflow of muscle activity, task and position specificity and sensory tricks (geste antagoniste), all recognized clinically for more than a century, are mediated by abnormal dystonia networks in which abnormal reflex activity to sensory inputs and sensory misprocessing play an important role. This section focuses on neurophysiological studies into these aspects.

\section{EMG studies in dystonia}

Early studies using surface electromyography (EMG) demonstrated co-contraction of agonist and antagonist muscles in a task-specific manner during handwriting in patients with writer's cramp (Rothwell et al. 1983). Patients with arm dystonia in the setting of idiopathic isolated segmental and generalized dystonia show abnormal co-contraction, muscle overflow activity and prolonged burst duration during voluntary elbow movements (Van der Kamp et al. 1989). Abnormal co-contraction in dystonia differs from voluntary co-contraction by virtue of abnormally coherent, synchronized motor unit activity driven by central descending input to motor neurons (Farmer et al. 1998). Reductions in lowfrequency $(4-12 \mathrm{~Hz})$ intermuscular EMG coherence activity occur after effective GPi DBS and partially correlate with clinical improvement (Doldersum et al. 2019). EMG studies in dystonia have also characterized myoclonic jerks in myoclonus dystonia (Obeso et al. 1983; Li et al. 2008) and rhythmic bursting activity corresponding to dystonic tremors (Jedynak et al. 1991).

\section{H-reflex and blink reflex in dystonia}

Reflex excitability is altered in dystonia and in general a pattern of reduced excitability of inhibitory circuits resulting in reduced inhibition has been observed. At the spinal cord level the H-reflex, the neurophysiological equivalent of a tendon jerk, is modulated by disynaptic and presynaptic inhibition by $1 \mathrm{a}$ afferents of the antagonist muscle, measured as H-reflex reciprocal inhibition, which is turn modified by excitability of local spinal cord circuits and descending input. H-reflex reciprocal inhibition is decreased in focal, segmental and generalized dystonia (Nakashima et al. 1989;
Panizza et al. 1989, 1990) even in unaffected limbs (Deuschl et al. 1992; Chen et al. 1995) consistent with an endophenotypic abnormality. Abnormally reduced presynaptic phase of H-reflex reciprocal inhibition is reversed after botulinum toxin therapy (Priori et al. 1995) likely due to denervation of intrafusal fibres and reduced muscle spindle afference (Giladi 1997; Rosales and Dressler 2010).

The blink reflex is characterised by an early oligosynaptic $\mathrm{R} 1$ and later polysynaptic R2 components. The R2 component displays paired pulse inhibition with repeated stimuli (Kimura and Harada 1976) mediated by brainstem inhibitory interneurons, themselves under control by projections from cerebral cortex, thalamus and basal ganglia (Berardelli et al. 1983). Blink reflexes thus provide a useful measure of brainstem excitability and indirectly probe basal ganglia output. Blink reflex R2 inhibition is abnormally decreased in patients with cranial (Berardelli et al. 1985), cervical (Tolosa et al. 1988), segmental and generalised dystonia including those without blepharospasm (Nakashima et al. 1990) and is present equally in manifesting and non-manifesting TOR1A/ DYT1 carriers (Fong et al. 2016). Unlike H-reflex reciprocal inhibition, blink reflex inhibition is normal in functional blepharospasm, and may assist in differentiating it from organic blepharospasm (Schwingenschuh et al. 2011).

\section{Effects of GPi DBS on reflex circuits}

GPi DBS restores abnormally reduced H-reflex reciprocal inhibition and blink reflex $\mathrm{R} 2$ inhibition in patients with generalized dystonia in a progressive time-course correlating with clinical improvement (see Fig. 2), indicating gradual normalisation of disinhibition within spinal and brainstem

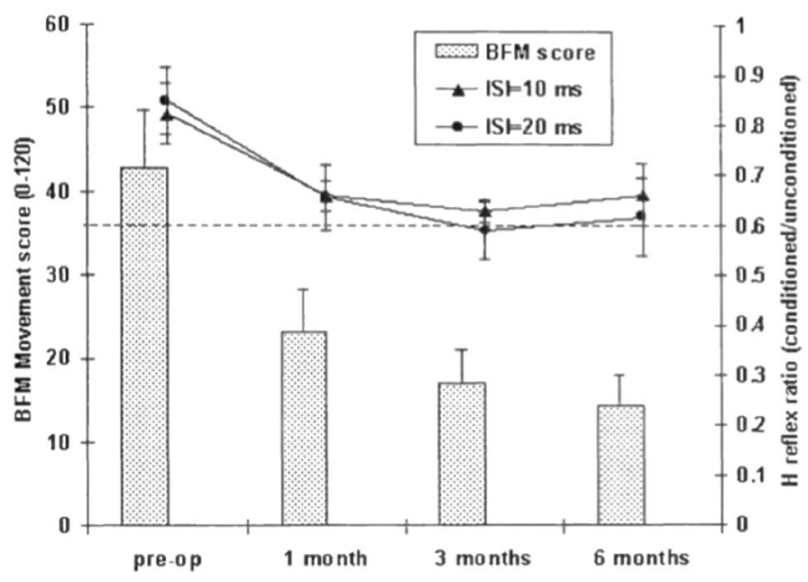

Fig. 2 Time-course of changes in presynaptic phase of H-reflex reciprocal inhibition (RI) after GPi DBS and clinical improvement. A line is superimposed at 0.6 , which represents a normal level of RI. Clinical improvement and changes in RI correlate and follow a logarithmic curve 
circuits as a marker or mechanism for clinical improvement ().

\section{Sensory processing in dystonia}

Sensory involvement in dystonia is evident clinically by potent temporary reduction in dystonic symptoms with specific sensory tricks (Leis et al. 1992), the finding that lesions of the sensory system both central (Lehericy et al. 2001) and peripheral (Jankovic and Linden 1988) may result in acquired dystonia and the presence of sensory symptoms among dystonia sufferers (Ghika et al. 1993; Stamelou et al. 2012). Neurophysiology studies have provided further insights into wide-ranging abnormalities of sensory processing in dystonia.

Peripheral sensory input in the form of tonic vibration of the muscle tendon in patients with writer's cramp worsens dystonic symptoms, while intramuscular injection of lignocaine improves dystonia, both effects likely mediated by alteration in muscle spindle afference, as anaesthetic inhibition of Ia fibres which mediate the tonic vibration response may help to compensate for loss of presynaptic inhibition in dystonia (Kaji et al. 1995).

In dystonia there is abnormal summation of cortical sensory evoked potentials in response to peripheral nerve stimulation (Tinazzi et al. 2000) and enlarged, dedifferentiated somatosensory receptive fields in thalamic receiving neurons such that the receptive field overflows from the sensory Vc thalamic nucleus to the cerebellar outflow-motor cortex relay Vim nucleus (Lenz et al. 1999). As mentioned, the hand representation within the somatosensory cortex is also distorted in dystonia including the asymptomatic side (Meunier et al. 2001). In patients with focal hand dystonia, tactile spatial discrimination is reduced (Bara-Jimenez et al. 2000a) and temporal discrimination of tactile and visuotactile stimuli is abnormally prolonged (Bara-Jimenez et al. 2000b; Fiorio et al. 2003). Sensory temporal discrimination is also prolonged non-manifesting TOR1A/DYT1 carriers (Fiorio et al. 2007) and unaffected first-degree relatives of dystonia sufferers in a frequency suggestive of an incompletely penetrant dominant gene (Kimmich et al. 2011), supporting an endophenotypic role for abnormal temporal discrimination in dystonia (Conte et al. 2017). A study using combined sensory temporal discrimination testing and evoked potentials indicated that prolonged tactile sensory discrimination thresholds are the result of reduced excitability of inhibitory circuits within the primary somatosensory cortex (Antelmi et al. 2017). Abnormally prolonged sensory temporal discrimination thresholds in dystonia can be further worsened by high-frequency peripheral sensory stimulation, suggesting abnormal plasticity with the primary somatosensory cortex (Erro et al. 2018). Perhaps surprisingly, in idiopathic isolated generalized dystonia tactile spatial sensory discrimination is normal (Molloy et al. 2003) and visual temporal discrimination thresholds are normal in patients with musician's dystonia (Maguire et al. 2020) perhaps reflecting better recompensation among elite musicians. Abnormally prolonged sensory temporal discrimination thresholds are present in functional dystonia to the same degree as organic dystonia (Morgante et al. 2011) interpreted as evidence for possible endophenotypic overlap between these disorders. Therapy studies indicate that abnormally prolonged sensory temporal discrimination thresholds in dystonia are not improved by GPi DBS (Sadnicka et al. 2013) or botox therapy (Scontrini et al. 2011). Preserved structural integrity of the sensory system, as determined by somatosensory evoked potentials (SSEPs) may help predict patients more likely to benefit from GPi DBS (McClelland et al. 2018). The effectiveness of sensory trick in cervical dystonia also appears to depend on the remaining integrity of sensory processing, as better visuotactile sensory discrimination correlates with effectiveness of sensory trick (Kägi et al. 2013).

Dystonia, in keeping with current models of a multilevel network disorder, discloses widespread sensory abnormalities, some of which may contribute to development of involuntary movements. The important concept of endophenotype is maintained, as many of the sensory abnormalities may be detected in clinically unaffected body parts or asymptomatic dystonia gene carriers. Future studies are needed to better elucidate environmental triggers and as yet unrecognized intrinsic and external modifying factors. GPi DBS exerts potent inhibition of motor symptoms of dystonia and long-term changes in brainstem and spinal excitability, but seems ineffective in altering sensory endophenotypic defects, which supports their probable upstream role in dystonia pathogenesis.

\section{Oscillatory activity recordings: local field potentials, microrecordings, EEG and evoked potentials}

Recording local oscillatory activity through DBS electrode contacts (local field potentials LFP) can provide some insight into the pathophysiology of dystonia, in particular through the pattern of activity of the basal gangliathalamo-cortical pathways. It can also inform us on the mechanisms of action of DBS. Single-cell recordings have been collected during DBS surgery, as part of the process of target localisation, and give us information at unicellular level. Cortical electrical activity recorded through EEG, electrocorticography (EcoG) or magnetic encephalography (MEG) allows to record activity at another point of the basal ganglia-thalamo-cortical circuitry. This activity has often been recorded in conjunction with basal ganglia LFP. Finally 
evoked potentials (EP) from the DBS pulse within the GPi have been recorded on the cortex.

\section{Local field potential and cortical recordings}

In Parkinson's disease (PD) many studies have reported increased activity not only in the beta band in the STN but also in GPi (Brown et al. 2001) and a correlation with bradykinesia (Beudel et al. 2017). In dystonia, most recordings have been done in the GPi as it is the preferred DBS target. Several studies have demonstrated an increased power in the low-frequency band $(4-12 \mathrm{~Hz})$ in the GPi of dystonic patients (Silberstein et al. 2003; Chen et al. 2006a; Liu et al. 2008; Neumann et al. 2012; Zhu et al. 2018). Correlations between this low-frequency activity and EMG activity have also been shown (Chen et al. 2006a). Using a measure assessing the direction of the coupling, Sharott et al. have shown that the coupling of GPi and the muscles is bidirectional and fluctuating but most of the drive was coming from GPi (Sharott et al. 2008). This low-frequency activity appears to be regulated by peripheral inputs, as demonstrated by a study on 'geste antagonist' in cervical dystonia (Tang et al. 2007a). The GPi LFP appear different in dystonia than other conditions such as Huntington disease (Zhu et al. 2018) and suggest that this activity has a role in the expression of the symptoms. LFP power in the $3-21 \mathrm{~Hz}$ band appears specific from GPi as it was also shown to be higher than in GPe (Chen et al. 2006b).

The LFP provide also information on the mechanism of action of DBS. The GPi low-frequency activity correlated with the severity of dystonia and a better outcome was observed if the stimulated contact was close to the maximum low-frequency peak (Neumann et al. 2017). A reduction of the mean power in the 4-12 $\mathrm{Hz}$ band was observed when DBS was switched on with a decrease in coherence between cortical EEG and GPi LFP in the same band $30 \mathrm{~s}$ after switching off DBS (Barow et al. 2014). These changes were observed in patients with phasic dystonia (Barow et al. 2014). Therefore, one of the mechanisms of action of GPi DBS might be through the suppression of abnormally synchronised low-frequency activity between GPi and the cortex.

LFP activity has also been recorded in the STN of dystonic patients, since the STN is also a target for dystonia, although less frequently used (Geng et al. 2017; Neumann et al. 2012). Low-frequency activity was also recorded in the STN in some studies (Geng et al. 2017; Neumann et al. 2012) although Wang et al. (2016) did not find any difference in the STN activity between dystonia and PD patients.

There are many different types of dystonia and not all dystonia would have the same LFP activity. Although GPi DBS can be offered to many different subtypes the outcome tends to be different according to the cause. Many studies have included isolated dystonia, generalised or focal and with or without an identified gene. Two patients with genetically proven myoclonus dystonia patients have also been studied and have shown coherence at $3-15 \mathrm{~Hz}$ between GPi and muscles (Foncke et al. 2007) similarly to isolated dystonia. Cervical dystonia has given rise to debate on the role of each GPi according to the pattern of muscle activation and direction of the cervical dystonia. In cervical dystonia interhemispheric differences have been measured in the 4-12 and $13-30 \mathrm{~Hz}$ bands (Lee and Kiss 2014). Another study has confirmed a lateralised difference at the level of GPi but not GPe (Moll et al. 2014). Sedov et al. have also found an asymmetry of discharge pattern and Gamma oscillations in 15 patients with cervical dystonia (Sedov et al. 2019a, b).

Most of the LFP recording was performed in the few days after surgery with externalised leads and before battery implantation. Local oedema and lasting effect of anaesthesia could affect those measures. Scheller et al. have recorded nine dystonic patients with long-term DBS using a Medtronic PC + S (Scheller et al. 2019). Patients were assessed with stimulation switched off for 5-7 h, the BFM rating scale was assessed and LFP were recorded. The level of low-frequency activity was associated with the dystonia severity even months after DBS implant and this was specific of that frequency band (Scheller et al. 2019).

It is also important to gain more understanding on the full range of frequency bands and how those activities change during different cognitive and motor tasks. Although some oscillations are probably responsible for the dystonic symptoms, others might still be important for physiological activity. As example it has been demonstrated that walking increased theta-alpha and reduced beta (Singh et al. 2011). Gamma activity has also been shown to change during movement and during cognitive tasks, having a possible role in motor learning (Brücke et al. 2008, 2012; Gillies et al. 2017; Tsang et al. 2012). How DBS affects those physiological frequency changed largely remains to be explored. The role of the low beta $(13-21 \mathrm{~Hz})$ cortico-pallidal coherence in initiation and execution of movement has been demonstrated but a lack of correlation with the severity of the dystonia was observed (Van Wijk et al. 2017; Singh et al. 2011; Tsang et al. 2012). Changes in the beta band have also been evidenced in the cortex or cortico-pallidal circuitry (Miocinovic et al. 2015; Neumann et al. 2015; Silberstein et al. 2003). Neumann et al. (2015) identified, with MEG and LFP, three networks: pallido temporal with theta $(4-8 \mathrm{~Hz})$ coherence, pallido cerebellar with alpha $(7-13 \mathrm{~Hz})$ coherence and cortico pallidal with beta $(13-30 \mathrm{~Hz})$ coherence. The last one had a cortical source and the other two a pallidal source. Only the pallido-cerebellar activity was inversely correlated to the severity of the dystonia. A study in 12 patients with generalised or focal isolated dystonia has shown a reduction of the excessive alpha oscillations over the motor cortex and 
interhemispheric alpha coherence during GPi or STN DBS (Miocinovic et al. 2018). This support the role of network desynchronization in the effect of DBS.

A study in 19 dystonic patients, 10 with phasic dystonia and 9 with tonic dystonia aimed at differentiating activity for these two types of symptoms. In patients with phasic dystonia peaks in the GPi oscillatory activities were observed in the alpha frequency range $(8-13 \mathrm{~Hz})$ and was functionally coupled across the GPi, GPe, and the motor cortex. In patients with tonic dystonia, delta oscillatory activities $(2-4 \mathrm{~Hz})$ were measured in the GPi with delta GPi-GPe functional coupling (Yokochi et al. 2018).

All the findings related to the role of low-frequency activity in the GPi of dystonia patients have led to the proposal to use this activity as a biomarker for adaptive DBS in dystonia (Neumann et al. 2017; Piña-Fuentes et al. 2019).

\section{Single-cell recordings}

Most studies on micro-recordings have reported that the signal recorded in GPi in patients with dystonia displays irregular grouped discharges with pauses (Vitek et al. 1999; Zhuang et al. 2004; Tang et al. 2007b). Several studies have compared activity in GPi of patients with dystonia and PD. GPi neurons in dystonia have been shown to have significantly lower discharge rates and more irregular discharge patterns than in PD (Vitek et al. 1999; Sanghera et al. 2003; Alam et al. 2016; Tang et al. 2007b; Starr et al. 2005). Higher number of bursts have also been identified in dystonia patients (Alam et al. 2016; Starr et al. 2005). The low-frequency rate has been inversely correlated with the severity of the dystonia (Starr et al. 2005).

Recordings in some studies have been done under general anaesthesia and the role of the anaesthetic agents on the recording is debated. Hutchinson argued that the lower discharge rate recorded in dystonia was an artefact from the use of Propofol (Hutchison et al. 2003). Steigerwald studied the effect of Propofol and concluded that the reduced discharge rate was a real observation (Steigerwald et al. 2005).

Some studies have focussed on the difference between GPi and GPe activity since this information is important for target localisation. In one of the early studies spontaneous discharge rates of GPi and GPe neurons were similar, and the two nuclei were distinguished by neuronal discharge patterns rather than rates (Starr et al. 2006). Sani et al. (2009) recorded pause in the awake human GPe that were characteristic and distinguished primary dystonia from PD and secondary dystonia. Their hypothesis was that they might reflect increased phasic input from striatal D2 receptor positive cells in primary dystonia and are consistent with a recent model proposing that GPe provides capacity scaling for cortical input. Interpause interval (IPI) was lower in primary dystonia (Sani et al. 2009).
Chen et al. (2006a) performed LFP and microrecording in awake dystonic patients to check if the LFP activity comes from the GPi neurones and not from volume conduction. They confirmed that the LFP in the $3-12 \mathrm{~Hz}$ band were synchronised to neuronal discharges recorded by microrecordings.

Microrecordings have also been done in the STN of patients implanted with dystonia and compared with PD showing also a lower discharge rate in patients with dystonia. Bursts were observed both in PD and dystonia (Schrock et al. 2009). Zhuang also recorded activity in the STN of dystonic patients and observed reduced rate and irregular bursts (Zhuang et al. 2004).

Devetiarov et al. (2017) have recorded activity on the ventral oral nucleus of the thalamus (Voi) and surrounding areas in patients with cervical dystonia and compared it to activity in the ventro-intermediate nucleus of the thalamus (Vim) in PD patients. Those patients were undergoing thalamotomy to treat their movement disorders. They identified single and burst pattern activities in all areas. They could not identify a disease specific pattern but there was a suggestion that Voa-Vop neurons in the surrounding areas were more hyperpolarised in dystonia because of the inhibitory pallidal outflow (Devetiarov 2017).

\section{Evoked potentials}

Evoked potentials (EP) from the DBS pulses within the GPi have been recorded on the cortex and contribute to our understanding of the mechanism of action of GPi DBS. The studies have demonstrated a peak in the central regions, likely to be the primary motor cortex, around $20-30 \mathrm{~ms}$ (Tisch et al. 2008; Bhanpuri et al. 2014; Ni et al. 2018). This peak is larger when the most effective contact is being stimulated and in good responders (Tisch et al. 2008; Bhanpuri et al. 2014). The fact that this peak was absent in a patient who had a previous thalamotomy, combined with the latency, suggest the involvement of the pallido-thalamocortical pathway (Tisch et al. 2008). In addition, coherence has been recorded in the beta band $(13-30 \mathrm{~Hz})$ between LFP recorded in GPi and motor and premotor oscillatory activity recorded with MEG (Neumann et al. 2015). Ni et al. identified two peaks in the central regions, in addition to the $25 \mathrm{~ms}$ peak, they identified an earlier peak at $10 \mathrm{~ms}$ (Ni et al. 2018). These two peaks had opposite polarity. The early peak was facilitatory and the later was inhibitory. This supports the hypothesis that the activation of the inhibitory output from GPi leads to inhibition of the motor cortex and normalisation of cortical plasticity in dystonia.

In summary dystonia severity appears related to GPi low frequency activity. One the mechanisms of action of DBS is probably through reducing this activity. This might be used as biomarker for adaptive DBS in 
the future. Nevertheless, the role of activities in other frequency bands and the effect of DBS on those activities need to be explored further. In addition, we do not know how these findings differ according to the type of dystonia. Microrecordings have confirmed that the low frequency activity recorded with LFP comes from the pallidal neurons and is relevant for the expression of the symptoms including real-time modulation of dystonic contractions by effective sensory tricks. Evoked potentials and recordings of cortical activity also support the role of an inhibition of the motor cortex mediated by the pallido-thalamo-cortical pathway. Finally, adaptive DBS approaches may differ for thalamic targets owing to added complexity of thalamic reorganisation in dystonia (Lenz et al. 1999).

\section{Conclusions}

Dystonia pathophysiology as elucidated by neurophysiology shows wide ranging abnormalities some of which normalise after clinically effective GPi DBS. The keys facts are summarised Table 1. Some changes, for example sensory misprocessing, are likely endophenotypic, providing a substrate for dystonia. Excessive motor cortex plasticity and low frequency pallidal output may play a more direct role in generating dystonic movements. GPi DBS reduces the dystonic symptoms, in proportion to reductions in excessive motor cortex plasticity and low-frequency activity suggesting an important mechanistic role. DBS is not a cure for dystonia and symptoms return after switching DBS off but benefits persist longer in those with more robust plasticity. While GPi DBS has proved a successful and beneficial intervention for dystonia, it has some

Table 1 Summary of physiology measures abnormalities in dystonia and the effect of GPi DBS

\begin{tabular}{|c|c|c|c|}
\hline Structure & Technique & Dystonia & Dystonia + GPi DBS \\
\hline \multirow[t]{2}{*}{ GPi } & Single cell & $\begin{array}{l}\text { Irregular groups discharges + pauses } \\
\text { Lower rate than PD } \\
\text { Higher bursts than PD } \\
\text { Low frequency correlation severity dystonia }\end{array}$ & \\
\hline & LFP & $\begin{array}{l}\text { Increased power low frequency band }(4-12 \mathrm{~Hz}) \\
\text { Correlation low frequency-EMG } \\
\text { Coupling GPi/muscles bidirectional, drive from GPi } \\
\text { Low frequency affected by peripheral input } \\
\text { Correlation low frequency severity dystonia } \\
\text { Phasic dystonia: alpha }(8-13 \mathrm{~Hz}) \text { coupling } \mathrm{GPi}, \mathrm{GPe} \text {, cortex } \\
\text { Tonic dystonia delta }(2-4 \mathrm{~Hz})\end{array}$ & $\begin{array}{l}\text { DBS near LF site more effective } \\
\text { DBS reduced mean power } 4-12 \mathrm{~Hz}\end{array}$ \\
\hline \multirow[t]{2}{*}{$\mathrm{GPe}$} & Single cells & $\begin{array}{l}\text { Different pattern than GPi } \\
\text { Pauses different than PD }\end{array}$ & \\
\hline & LFP & Lower power in low frequency band than GPi & \\
\hline \multirow[t]{2}{*}{ STN } & Single cell & $\begin{array}{l}\text { Lower rate than PD } \\
\text { Bursts }\end{array}$ & \\
\hline & LFP & Low frequency & \\
\hline Thalamus (Voi) & Single cell & Single activity and bursts & \\
\hline Pallido-cortical & EP from GPi & $\begin{array}{l}\text { Pallido-temporal theta }(4-8 \mathrm{~Hz}) \\
\text { Pallido-cerebellar alpha }(7-13 \mathrm{~Hz}) \text { inverse correlation sever- } \\
\text { ity } \\
\text { Cortico-pallidal Beta }(13-30 \mathrm{~Hz}) \\
\text { peak motor cortex } 20-30 \mathrm{~ms} \text {; larger effective contact and if } \\
\text { good response (inhibitory) } \\
\text { Earlier peak } 10 \mathrm{~ms} \text { (facilitatory) }\end{array}$ & DBS reduced cortico-pallidal coherence \\
\hline Cortex & $\begin{array}{l}\text { EEG } \\
\text { TMS }\end{array}$ & $\begin{array}{l}\text { Abnormal excessive synchronised } 4-12 \mathrm{~Hz} \text { activity } \\
\text { Reduced motor cortex intracortical inhibition and silent } \\
\text { period } \\
\text { Increased motor cortex plasticity } \\
\text { Pre-motor to motor cortex interactions }\end{array}$ & $\begin{array}{l}\text { DBS reduced alpha oscillations motor cortex } \\
\text { DBS reduces interhemispheric alpha coherence } \\
\text { DBS slightly increases motor cortex excitability } \\
\text { DBS over time increases SICI } \\
\text { DBS reduces excessive motor cortex plasticity } \\
\text { Effects of DBS unknown }\end{array}$ \\
\hline Brainstem & Blink reflex & Reduced blink reflex R2 inhibition & DBS normalises R2 disinhibition \\
\hline Spinal cord & H-reflex & Reduced H-reflex reciprocal inhibition & DBS normalises reduced reciprocal inhibition \\
\hline Muscle & LFP + EMG & Correlations GPi activity and EMG & \\
\hline
\end{tabular}


potential side effects including stimulation-induced Parkinsonian features (Tisch et al. 2007c; Mahlknecht et al. 2018; Kosutzka et al. 2020). Further refinements of DBS including adaptive stimulation may allow improvement in DBS efficacy and side effect profile. Neurophysiology studies will remain essential in furthering our understanding of both dystonia and DBS action.

Acknowledgements The authors wish to acknowledge Prof John Rothwell and his extensive work in neurophysiology and movement disorders, which represents a unique contribution to the field. The authors also wish to sincerely thank Prof John Rothwell for his invaluable support in their own training and careers.

Funding Not applicable.

\section{Compliance with ethical standards}

Conflict of interest P Limousin has received lecture honorarium from Medtronic and Boston Scientific and a grant from Boston Scientific.

Open Access This article is licensed under a Creative Commons Attribution 4.0 International License, which permits use, sharing, adaptation, distribution and reproduction in any medium or format, as long as you give appropriate credit to the original author(s) and the source, provide a link to the Creative Commons licence, and indicate if changes were made. The images or other third party material in this article are included in the article's Creative Commons licence, unless indicated otherwise in a credit line to the material. If material is not included in the article's Creative Commons licence and your intended use is not permitted by statutory regulation or exceeds the permitted use, you will need to obtain permission directly from the copyright holder. To view a copy of this licence, visit http://creativecommons.org/licenses/by/4.0/.

\section{References}

Alam M, Sanghera MK, Schwabe K, Lütjens G, Jin X, Song J, von Wrangel C, Stewart RM, Jankovic J, Grossman RG, Darbin O, Krauss JK (2016) Globus pallidus internus neuronal activity: a comparative study of linear and non-linear features in patients with dystonia or Parkinson's disease. J Neural Transm (Vienna) 123:231-240

Albanese A, Bhatia K, Bressman SB, Delong MR, Fahn S, Fung VS, Hallett M, Jankovic J, Jinnah HA, Klein C, Lang AE, Mink JW, Teller JK (2013) Phenomenology and classification of dystonia: a consensus update. Mov Disord 28:863-873

Antelmi E, Erro R, Rocchi L, Liguori R, Di TM, Stasio F, Berardelli A, Rothwell JC, Bhatia KP (2017) Neurophysiological correlates of abnormal somatosensory temporal discrimination in dystonia. Mov Disord 32:141-148

Avanzino L, Martino D, van de Warrenburg BP, Schneider SA, Abbruzzese G, Defazio G, Schrag A, Bhatia KP, Rothwell JC (2008) Cortical excitability is abnormal in patients with the "fixed dystonia" syndrome. Mov Disord 23:646-652

Bara-Jimenez W, Shelton P, Sanger TD, Hallett M (2000b) Sensory discrimination capabilities in patients with focal hand dystonia. Ann Neurol 47:377-380

Bara-Jimenez W, Shelton P, Hallett M (2000a) Spatial discrimination is abnormal in focal hand dystonia. Neurology 55:1869-1873
Barker AJ, Jalinous R, Freeston IL (1985) Non-invasive stimulation of human motor cortex. Lancet 1:1106-1107

Barow E, Neumann WJ, Brücke C, Huebl J, Horn A, Brown P, Krauss JK, Schneider GH, Kühn AA (2014) Deep brain stimulation suppresses pallidal low frequency activity in patients with phasic dystonic movements. Brain 137:3012-3024

Bäumer T, Demiralay C, Hidding U, Bikmullina R, Helmich RC, Wunderlich S, Rothwell J, Liepert J, Siebner HR, Münchau A (2007) Abnormal plasticity of the sensorimotor cortex to slow repetitive transcranial magnetic stimulation in patients with writer's cramp. Mov Disord 22:81-90

Berardelli A, Accomero N, Cruccu G, Fabiano F, Guerrisi V, Manfredi M (1983) The orbicularis oculi response after hemispheral damage. J Neurol Neurosurg Psychiatry 46:837-843

Berardelli A, Rothwell JC, Day BL, Marsden CD (1985) Pathophysiology of blepharospasm and oromandibular dystonia. Brain 108:593-608

Beudel M, Oswal A, Jha A, Foltynie T, Zrinzo L, Hariz M, Limousin P, Litvak V (2017) Oscillatory beta power correlates with akinesia-rigidity in the Parkinsonian subthalamic nucleus. Mov Disord 32:174-175

Bhanpuri NH, Bertucco M, Ferman D, Young SJ, Liker MA, Krieger MD, Sanger TD (2014) Deep brain stimulation evoked potentials may relate to clinical benefit in childhood dystonia. Brain Stimul 7:718-726

Brown P, Oliviero A, Mazzone P, Insola A, Tonali P, Di Lazzaro V (2001) Dopamine dependency of oscillations between subthalamic nucleus and pallidum in Parkinson's disease. J Neurosci 21:1033-1038

Brücke C, Kempf F, Kupsch A, Schneider GH, Krauss JK, Aziz T, Yarrow K, Pogosyan A, Brown P, Kühn AA (2008) Movementrelated synchronization of gamma activity is lateralized in patients with dystonia. Eur J Neurosci 27:2322-2329

Brücke C, Huebl J, Schönecker T, Neumann WJ, Yarrow K, Kupsch A, Blahak C, Lütjens G, Brown P, Krauss JK, Schneider GH, Kühn AA (2012) Scaling of movement is related to pallidal $\gamma$ oscillations in patients with dystonia. J Neurosci 32:1008-1019

Chen RS, Tsai CH, Lu CS (1995) Reciprocal inhibition in writer's cramp. Mov Disord 10:556-561

Chen R, Wassermann EM, Canos M, Hallett M (1997a) Impaired inhibition in writer's cramp during voluntary muscle activation. Neurology 49:1054-1059

Chen R, Classen J, Gerloff C, Celnik P, Wassermann EM, Hallett M, Cohen LG (1997b) Depression of motor cortex excitability by low-frequency transcranial magnetic stimulation. Neurology 48:1398-1403

Chen CC, Kühn AA, Hoffmann KT, Kupsch A, Schneider GH, Trottenberg T, Krauss JK, Wöhrle JC, Bardinet E, Yelnik J, Brown P (2006a) Oscillatory pallidal local field potential activity correlates with involuntary EMG in dystonia. Neurology $66: 418-420$

Chen CC, Kühn AA, Trottenberg T, Kupsch A, Schneider GH, Brown P (2006b) Neuronal activity in globus pallidus interna can be synchronized to local field potential activity over $3-12 \mathrm{~Hz}$ in patients with dystonia. Exp Neurol 202:480-486

Chung M, Huh R (2016) Different clinical course of pallidal deep brain stimulation for phasic- and tonic-type cervical dystonia. Acta Neurochir (Wien) 158:171-180

Conte A, McGovern EM, Narasimham S, Beck R, Killian O, O'Riordan S, Reilly RB, Hutchinson M (2017) Temporal discrimination: mechanisms and relevance to adult-onset dystonia. Front Neurol 28(8):625

Coubes P, Roubertie A, Vayssiere N, Hemm S, Echenne B (2000) Treatment of DYT1-generalised dystonia by stimulation of the internal globus pallidus. Lancet 355:2220-2221 
Detante O, Vercueil L, Thobois S, Broussolle E, Costes N, Lavenne F, Chabardes S, Lebars D, Vidailhet M, Benabid AL, Poliak P (2004) Globus pallidus intemus stimulation in primary generalized dystonia: a H2150 PET study. Brain 127:1899-1908

Deuschl G, Seifert C, Heinen F, Illert M, Lucking CH (1992) Reciprocal inhibition of forearm flexor muscles in spasmodic torticollis. J Neurol Sci 113:85-90

Devetiarov D, Semenova U, Usova S, Tomskiy A, Tyurnikov V, Nizametdinova D, Gushcha A, Belova E, Sedov A (2017) Neuronal activity patterns in the ventral thalamus: comparison between Parkinson's disease and cervical dystonia. Clin Neurophysiol 128:2482-2490

Doldersum E, van Zijl JC, Beudel M, Eggink H, Brandsma R, PiñaFuentes D, van Egmond ME, Oterdoom DLM, van Dijk JMC, Elting JWJ, Tijssen MAJ (2019) Intermuscular coherence as biomarker for pallidal deep brain stimulation efficacy in dystonia. Clin Neurophysiol 130:1351-1357

Edwards MJ, Huang YZ, Mir P, Rothwell JC, Bhatia KP (2006) Abnormalities in motor cortical plasticity differentiate manifesting and nonmanifesting DYT1 carriers. Mov Disord 21:2181-2186

Erro R, Rocchi L, Antelmi E, Liguori R, Tinazzi M, Berardelli A, Rothwell J, Bhatia KP (2018) High frequency somatosensory stimulation in dystonia: evidence for defective inhibitory plasticity. Mov Disord 33:1902-1909

Espay AJ, Morgante F, Purzner J, Gunraj CA, Lang AE, Chen R (2006) Cortical and spinal abnormalities in psychogenic dystonia. Ann Neurol 59:825-834

Fahn S (1988) Concept and classification of dystonia. Adv Neurol 50:1-8

Farmer SF, Sheean GL, Mayston MJ, Rothwell JC, Marsden CD, Conway BA, Halliday DM, Rosenberg JR, Stephens JA (1998) Abnormal motor unit synchronization of antagonist muscles underlies pathological co-contraction in upper limb dystonia. Brain 121:801-814

Fiorio M, Tinazzi M, Bertolasi L, Aglioti SM (2003) Temporal processing of visuotactile and tactile stimuli in writer's cramp. Ann Neurol 53:630-635

Fiorio M, Gambarin M, Valente EM, Liberini P, Loi M, Cossu G, Moretto G, Bhatia KP, Defazio G, Aglioti SM, Fiaschi A, Tinazzi M (2007) Defective temporal processing of sensory stimuli in DYT1 mutation carriers: a new endophenotype of dystonia? Brain 130:134-142

Foncke EM, Bour LJ, Speelman JD, Koelman JH, Tijssen MA (2007) Local field potentials and oscillatory activity of the internal globus pallidus in myoclonus-dystonia. Mov Disord 22:369-376

Fong PY, Edwards MJ, Lu CS, Chen RS, Rothwell JC, Bhatia KP, Huang YZ (2016) Abnormal blink reflex recovery cycle in manifesting and nonmanifesting carriers of the DYT1 gene mutation. NeuroReport 27:1046-1049

Geng X, Zhang J, Jiang Y, Ashkan K, Foltynie T, Limousin P, Zrinzo L, Green A, Aziz T, Brown P, Wang S (2017) Comparison of oscillatory activity in subthalamic nucleus in Parkinson's disease and dystonia. Neurobiol Dis 98:100-107

Ghika J, Regli F, Growdon JH (1993) Sensory symptoms in cranial dystonia: a potential role in the etiology? J Neurol Sci 116:142-147

Giladi N (1997) The mechanism of action of botulinum toxin type A in focal dystonia is most probably through its dual effect on efferent (motor) and afferent pathways at the injected site. J Neurol Sci 152:132-135

Gilio F, Curra A, Inghilleri M, Lorenzano C, Suppa A, Manfredi M, Berardelli A (2003) Abnormalities of motor cortex excitability preceding movement in patients with dystonia. Brain 126:1745-1754
Gillies MJ, Hyam JA, Weiss AR, Antoniades CA, Bogacz R, Fitzgerald JJ, Aziz TZ, Whittington MA, Green AL (2017) The cognitive role of the globus pallidus interna; insights from disease states. Exp Brain Res 235:1455-1465

Hallet M (2004) Dystonia: abnormal movements result from loss of inhibition. Adv Neurol 94:1-9

Huang YZ, Edwards MJ, Rounis E, Bhatia KP, Rothwell JC (2005) Theta burst stimulation of the human motor cortex. Neuron 45:201-206

Hubsch C, Roze E, Popa T, Russo M, Balachandran A, Pradeep S, Mueller F, Brochard V, Quartarone A, Degos B, Vidailhet M, Kishore A, Meunier S (2013) Defective cerebellar control of cortical plasticity in writer's cramp. Brain 136:2050-2062

Hutchison WD, Lang AE, Dostrovsky JO, Lozano AM (2003) Pallidal neuronal activity: implications for models of dystonia. Ann Neurol 53:480-488

Jankovic J, Van der Linden C (1988) Dystonia and tremor induced by peripheral trauma: predisposing factors. J Neurol Neurosurg Psychiatry 51:1512-1519

Jedynak CP, Bonnet AM, Agid Y (1991) Tremor and idiopathic dystonia. Mov Disord 6:230-236

Kägi G, Katschnig P, Fiorio M, Tinazzi M, Ruge D, Rothwell J, Bhatia KP (2013) Sensory tricks in primary cervical dystonia depend on visuotactile temporal discrimination. Mov Disord 28:356-361

Kaji R, Rothwell JC, Katayama M, Ikeda T, Kubori T, Kohara N, Mezaki T, Shibasaki H, Kimura J (1995) Tonic vibration reflex and muscle afferent block in writer's cramp. Ann Neurol 38:155-162

Khedr EM, Rothwell JC, Ahmed MA, Shawky OA, Farouk M (2007) Modulation of motor cortical excitability following rapidrate transcranial magnetic stimulation. Clin Neurophysiol 118:140-145

Kimmich O, Bradley D, Whelan R, Mulrooney N, Reilly RB, Hutchinson S, O'Riordan S, Hutchinson M (2011) Sporadic adult onset primary torsion dystonia is a genetic disorder by the temporal discrimination test. Brain 134:2656-2663

Kimura J, Harada O (1976) Recovery curves of the blink reflex during wakefulness and sleep. J Neurol 213:189-198

Kosutzka Z, Rivaud-Pechoux S, Pouget P, Bonnet C, Tisch S, Roze E, Grabli D, Gaymard B, Yelnik J, Habert MO, Vidailhet M (2020) Pathophysiology of gait disorders induced by bilateral globus pallidus interna stimulation in dystonia. Brain 143:e3

Krauss JK, Pohle T, Weber S, Ozdoba C, Burgunder JM (1999) Bilateral stimulation of globus pallidus internus for treatment of cervical dystonia. Lancet 354:837-838

Kuhn AA, Meyer BU, Trottenberg T, Brandt SA, Schneider GH, Kupsch A (2003) Modulation of motor cortex excitability by pallidal stimulation in patients with severe dystonia. Neurology 60:768-774

Kumar R, Dagher A, Hutchison WD, Lang AE, Lozano AM (1999) Globus pallidus deep brain stimulation for generalized dystonia: clinical and PET investigation. Neurology 53:871-874

Kupsch A, Benecke R, Müller J, Trottenberg T, Schneider GH, Poewe W, Eisner W, Wolters A, Müller JU, Deuschl G, Pinsker MO, Skogseid IM, Roeste GK, Vollmer-Haase J, Brentrup A, Krause M, Tronnier V, Schnitzler A, Voges J, Nikkhah G, Vesper J, Naumann M, Volkmann J, Deep-Brain Stimulation for Dystonia Study Group (2006) Pallidal deep-brain stimulation in primary generalized or segmental dystonia. N Engl J Med 355:1978-1990

Lee JR, Kiss ZH (2014) Interhemispheric difference of pallidal local field potential activity in cervical dystonia. J Neurol Neurosurg Psychiatry 85:306-310

Lehéricy S, Grand S, Pollak P, Poupon F, Le Bas JF, Limousin P, Jedynak P, Marsault C, Agid Y, Vidailhet M (2001) Clinical characteristics and topography of lesions in movement disorders due to thalamic lesions. Neurology 57:1055-1066 
Leis AA, Dimitrijevic MR, Delapasse JS, Sharkey PC (1992) Modification of cervical dystonia by selective sensory stimulation. J Neurol Sci 110:79-89

Lenz FA, Jaeger CJ, Seike MS, Lin YC, Reich SG, DeLong MR, Vitek JL (1999) Thalamic single neuron activity in patients with dystonia: dystonia-related activity and somatic sensory reorganization. J Neurophysiol 82:2372-2392

Liu X, Wang S, Yianni J, Nandi D, Bain PG, Gregory R, Stein JF, Aziz TZ (2008) The sensory and motor representation of synchronized oscillations in the globus pallidus in patients with primary dystonia. Brain 131:1562-1573

Li JY, Cunic DI, Paradiso G, Gunraj C, Pal PK, Lang AE, Chen R (2008) Electrophysiological features of myoclonus-dystonia. Mov Disord 23:2055-2061

Maguire F, Reilly RB, Simonyan K (2020) Normal temporal discrimination in musician's dystonia is linked to aberrant sensorimotor processing. Mov Disord. https://doi.org/10.1002/mds.27984 (Epub ahead of print)

Mahlknecht P, Georgiev D, Akram H, Brugger F, Vinke S, Zrinzo L, Hariz M, Bhatia KP, Hariz GM, Willeit P, Rothwell JC, Foltynie T, Limousin P (2018) Parkinsonian signs in patients with cervical dystonia treated with pallidal deep brain stimulation. Brain 141:3023-3034

McClelland VM, Fialho D, Flexney-Briscoe D, Holder GE, Elze MC, Gimeno H, Siddiqui A, Mills K, Selway R, Lin JP (2018) Somatosensory evoked potentials and central motor conduction times in children with dystonia and their correlation with outcomes from deep brain stimulation of the globus pallidus internus. Clin Neurophysiol 129:473-486

Meunier S, Gamero L, Ducorps A, Mazieres L, Lehericy S, du Montcel ST, Renault B, Vidailhet M (2001) Human brain mapping in dystonia reveals both endophenotypic traits and adaptive reorganization. Ann Neurol 50:521-527

Mink JW (1996) The basal ganglia: focused selection and inhibition of competing motor programs. Prog Neurobiol 50:381-425

Miocinovic S, de Hemptinne C, Qasim S, Ostrem JL, Starr PA (2015) Patterns of cortical synchronization in isolated dystonia compared with parkinson disease. JAMA Neurol 72:1244-1251

Miocinovic S, Miller A, Swann NC, Ostrem JL, Starr PA (2018) Chronic DBS reduces exaggerated alpha oscillations and interhemispheric alpha coherence in the motor cortex of patients with isolated dystonia. Chronic deep brain stimulation normalizes scalp EEG activity in isolated dystonia. Clin Neurophysiol 129:368-376

Molloy FM, Carr TD, Zeuner KE, Dambrosia JM, Hallet M (2003) Abnormalities of spatial discrimination in focal and generalized dystonia. Brain 126:2175-2182

Moll CK, Galindo-Leon E, Sharott A, Gulberti A, Buhmann C, Koeppen JA, Biermann M, Bäumer T, Zittel S, Westphal M, Gerloff C, Hamel W, Münchau A, Engel AK (2014) Asymmetric pallidal neuronal activity in patients with cervical dystonia. Front Syst Neurosci 11(8): 15

Morgante F, Tinazzi M, Squintani G, Martino D, Defazio G, Romito L, Albanese A, Di Matteo A, Quartarone A, Girlanda P, Fiorio M, Berardelli A (2011) Abnormal tactile temporal discrimination in psychogenic dystonia. Neurology 77:1191-1197

Murase N, Rothwell JC, Kaji R, Urushihara R, Nakamura K, Murayama N, Igasaki T, Sakata-Igasaki M, Mima T, Ikeda A, Shibasaki H (2005) Subthreshold low-frequency repetitive transcranial magnetic stimulation over the premotor cortex modulates writer's cramp. Brain 128:104-115

Nakashima K, Rothwell JC, Day BL, Thompson PD, Shannon K, Marsden CD (1989) Reciprocal inhibition between forearm muscles in patients with writer's cramp and other occupational cramps, symptomatic hemidystonia and hemiparesis due to stroke. Brain 112:681-697
Nakashima K, Rothwell JC, Thompson PD, Day BL, Berardelli A, Agostino R, Artieda J, Papas SM, Obeso JA, Marsden CD (1990) The blink reflex in patients with idiopathic torsion dystonia. Arch Neurol 47:413-416

Neumann WJ, Huebl J, Brücke C, Ruiz MH, Kupsch A, Schneider GH, Kühn AA (2012) Enhanced low-frequency oscillatory activity of the subthalamic nucleus in a patient with dystonia. Mov Disord 27:1063-1066

Neumann WJ, Jha A, Bock A, Huebl J, Horn A, Schneider GH, Sander TH, Litvak V, Kühn AA (2015) Cortico-pallidal oscillatory connectivity in patients with dystonia. Brain 138:1894-1906

Neumann WJ, Horn A, Ewert S, Huebl J, Brücke C, Slentz C, Schneider GH, Kühn AA (2017) A localized pallidal physiomarker in cervical dystonia. Ann Neurol 82:912-924

Nitsche MA, Roth A, Kuo MF, Fischer AK, Liebetanz D, Lang N, Tergau F, Paulus W (2007) Timing-dependent modulation of associative plasticity by general network excitability in the human motor cortex. J Neurosci 27:3807-3812

Ni Z, Kim SJ, Phielipp N, Ghosh S, Udupa K, Gunraj CA, Saha U, Hodaie M, Kalia SK, Lozano AM, Lee DJ, Moro E, Fasano A, Hallett M, Lang AE, Chen R (2018) Pallidal deep brain stimulation modulates cortical excitability and plasticity. Ann Neurol $83: 352-362$

Obeso JA, Rothwell JC, Lang AE, Marsden CD (1983) Myoclonic dystonia. Neurology 33:825-830

Panizza ME, Hallett M, Nilsson J (1989) Reciprocal inhibition in patients with hand cramps. Neurology 39:85-89

Panizza M, Lelli S, Nilsson J, Hallett M (1990) H-reflex recovery curve and reciprocal inhibition of H-reflex in different kinds of dystonia. Neurology 40:824-828

Peinemann A, Reimer B, Loer C, Quartarone A, Munchau A, Conrad B, Siebner HR (2004) Long-lasting increase in corticospinal excitability after 1800 pulses of subthreshold $5 \mathrm{~Hz}$ repetitive TMS to the primary motor cortex. Clin Neurophysiol 115:1519-1526

Piña-Fuentes D, van Zijl JC, van Dijk JMC, Little S, Tinkhauser G, Oterdoom DLM, Tijssen MAJ, Beudel M (2019) The characteristics of pallidal low-frequency and beta bursts could help implementing adaptive brain stimulation in the parkinsonian and dystonic internal globus pallidus. Neurobiol Dis 121:47-57

Priori A, Berardelli A, Mercuri B, Manfredi M (1995) Physiological effects produced by botulinum toxin treatment of upper limb dystonia. Changes in reciprocal inhibition between forearm muscles. Brain 118:801-807

Quartarone A, Bagnato S, Rizzo V, Siebner HR, Dattola V, Scalfari A, Morgante F, Battaglia F, Romano M, Girlanda P (2003) Abnormal associative plasticity of the human motor cortex in writer's cramp. Brain 126:2586-2596

Quartarone A, Rizzo V, Terranova C, Morgante F, Schneider S, Ibrahim N, Girlanda P, Bhatia KP, Rothwell JC (2009) Abnormal sensorimotor plasticity in organic but not in psychogenic dystonia. Brain 132:2871-2877

Richardson SP, Beck S, Bliem B, Hallett M (2014) Abnormal dorsal premotor-motor inhibition in writer's cramp. Mov Disord 29:797-803

Ridding MC, Sheean G, Rothwell JC, Inzelberg R, Kujirai T (1995) Changes in the balance between motor cortical excitation and inhibition in focal, task specific dystonia. J Neurol Neurosurg Psychiatry 59:493-498

Rona S, Berardelli A, Vacca L, Inghilleri M, Manfredi M (1998) Alterations of motor cortical inhibition in patients with dystonia. Mov Disord 13:118-124

Rosales RL, Dressler D (2010) On muscle spindles, dystonia and botulinum toxin. Eur J Neurol 17(Suppl 1):71-80

Rosenkranz K, Williamson A, Butler K, Cordivari C, Lees AJ, Rothwell JC (2005) Pathophysiological differences between musician's dystonia and writer's cramp. Brain 128:918-931 
Rothwell JC (1991) Physiological studies of electric and magnetic stimulation of the human brain. Electroencephalogr Clin Neurophysiol Suppl 43:29-35

Rothwell JC, Obeso JA, Day BL, Marsden CD (1983) Pathophysiology of dystonias. Adv Neurol 39:851-863

Ruge D, Tisch S, Hariz MI, Zrinzo L, Bhatia KP, Quinn NP, Jahanshahi M, Limousin P, Rothwell JC (2011a) Deep brain stimulation effects in dystonia: time course of electrophysiological changes in early treatment. Mov Disord 26:1913-1921

Ruge D, Cif L, Limousin P, Gonzalez V, Vasques X, Hariz MI, Coubes P, Rothwell JC (2011b) Shaping reversibility? Long-term deep brain stimulation in dystonia: the relationship between effects on electrophysiology and clinical symptoms. Brain 134:2106-2115

Sadnicka A, Kimmich O, Pisarek C, Ruge D, Galea J, Kassavetis P, Pareés I, Saifee T, Molloy A, Bradley D, O’Riordan S, Zrinzo L, Hariz M, Bhatia KP, Limousin P, Foltynie T, Rothwell JC, Hutchinson M, Edwards MJ (2013) Pallidal stimulation for cervical dystonia does not correct abnormal temporal discrimination. Mov Disord 28:1874-1877

Sanghera MK, Grossman RG, Kalhorn CG, Hamilton WJ, Ondo WG, Jankovic J (2003) Basal ganglia neuronal discharge in primary and secondary dystonia in patients undergoing pallidotomy. Neurosurgery 52:1358-1370

Sani S, Ostrem JL, Shimamoto S, Levesque N, Starr PA (2009) Single unit "pauser" characteristics of the globus pallidus pars externa distinguish primary dystonia from secondary dystonia and Parkinson's disease. Exp Neurol 216:295-299

Scheller U, Lofredi R, van Wijk BCM, Saryyeva A, Krauss JK, Schneider GH, Kroneberg D, Krause P, Neumann WJ, Kühn AA (2019) Pallidal low-frequency activity in dystonia after cessation of long-term deep brain stimulation. Mov Disord 34:1734-1739

Schrock LE, Ostrem JL, Turner RS, Shimamoto SA, Starr PA (2009) The subthalamic nucleus in primary dystonia: single-unit discharge characteristics. J Neurophysiol 102:3740-3752

Schwingenschuh P, Katschnig P, Edwards MJ, Teo JTH, Korlipara LVP, Rothwell JC, Bhatia KP (2011) The blink reflex recovery cycle differs between essential and presumed psychogenic blepharospasm. Neurology 76:610-614

Scontrini A, Conte A, Fabbrini G, Colosimo C, Di Stasio F, Ferrazzano G, Berardelli A (2011) Somatosensory temporal discrimination tested in patients receiving botulinum toxin injection for cervical dystonia. Mov Disord 26:742-746

Sedov A, Semenova U, Usova S, Tomskiy A, Crawford JD, Jinnah HA, Shaikh AG (2019a) Implications of asymmetric neural activity patterns in the basal ganglia outflow in the integrative neural network model for cervical dystonia. Prog Brain Res 249:261-268

Sedov A, Usova S, Semenova U, Gamaleya A, Tomskiy A, Crawford JD, Corneil B, Jinnah HA, Shaikh AG (2019b) The role of pallidum in the neural integrator model of cervical dystonia. Neurobiol Dis 125:45-54

Sharott A, Grosse P, Kühn AA, Salih F, Engel AK, Kupsch A, Schneider GH, Krauss JK, Brown P (2008) Is the synchronization between pallidal and muscle activity in primary dystonia due to peripheral afferance or a motor drive? Brain 131:473-484

Siebner HR, Filipovic SR, Rowe JB, Cordivari C, Gerschlager W, Rothwell JC, Frackowiak RS, Bhatia KP (2003) Patients with focal arm dystonia have increased sensitivity to slow-frequency repetitive TMS of the dorsal premotor cortex. Brain 126:2710-2725

Silberstein P, Kühn AA, Kupsch A, Trottenberg T, Krauss JK, Wöhrle JC, Mazzone P, Insola A, Di Lazzaro V, Oliviero A, Aziz T, Brown P (2003) Patterning of globus pallidus local field potentials differs between Parkinson's disease and dystonia. Brain 126:2597-2608

Singh A, Kammermeier S, Plate A, Mehrkens JH, Ilmberger J, Bötzel K (2011) Pattern of local field potential activity in the globus pallidus internum of dystonic patients during walking on a treadmill. Exp Neurol 232:162-167

Stamelou M, Edwards MJ, Hallett M, Bhatia KP (2012) The non-motor syndrome of primary dystonia: clinical and pathophysiological implications. Brain 135:1668-1681

Starr PA, Rau GM, Davis V, Marks WJ Jr, Ostrem JL, Simmons D, Lindsey N, Turner RS (2005) Spontaneous pallidal neuronal activity in human dystonia: comparison with Parkinson's disease and normal macaque. J Neurophysiol 93:3165-3176

Starr PA, Turner RS, Rau G, Lindsey N, Heath S, Volz M, Ostrem JL, Marks WJ Jr (2006) Microelectrode-guided implantation of deep brain stimulators into the globus pallidus internus for dystonia: techniques, electrode locations, and outcomes. J Neurosurg 104:488-501

Stefan K, Kunesch E, Cohen LG, Benecke R, Classen J (2000) Induction of plasticity in the human motor cortex by paired associative stimulation. Brain 123:572-584

Stefan K, Kunesch E, Benecke R, Cohen LG, Classen J (2002) Mechanisms of enhancement of human motor cortex excitability induced by interventional paired associative stimulation. $\mathrm{J}$ Physiol 543:699-708

Steigerwald F, Hinz L, Pinsker MO, Herzog J, Stiller RU, Kopper F, Mehdorn HM, Deuschl G, Volkmann J (2005) Effect of propofol anesthesia on pallidal neuronal discharges in generalized dystonia. Neurosci Lett 386:156-159

Stinear CM, Byblow WD (2004) Impaired modulation of intracortical inhibition in focal hand dystonia. Cereb Cortex 14:555-561

Tang JK, Mahant N, Cunic D, Chen R, Moro E, Lang AE, Lozano AM, Hutchison WD, Dostrovsky JO (2007a) Changes in cortical and pallidal oscillatory activity during the execution of a sensory trick in patients with cervical dystonia. Exp Neurol 204:845-848

Tang JK, Moro E, Mahant N, Hutchison WD, Lang AE, Lozano AM, Dostrovsky JO (2007b) Neuronal firing rates and patterns in the globus pallidus internus of patients with cervical dystonia differ from those with Parkinson's disease. J Neurophysiol 98:720-729

Tinazzi M, Priori A, Bertolasi L, Frasson E, Mauguiere F, Fiaschi A (2000) Abnormal central integration of a dual somatosensory input in dystonia. Evid Sens Overflow Brain 123:42-50

Tisch S (2018) Recent advances in understanding and managing dystonia. F1000Res 7:1124

Tisch S, Limousin P, Rothwell JC, Asselman P, Zrinzo L, Jahanshahi M, Bhatia KP, Hariz MI (2006a) Changes in forearm reciprocal inhibition following pallidal stimulation for dystonia. Neurology 66:1091-1093

Tisch S, Limousin P, Rothwell JC, Asselman P, Quinn N, Jahanshahi M, Bhatia KP, Hariz M (2006b) Changes in blink reflex excitability after globus pallidus internus stimulation for dystonia. Mov Disord 21:1650-1655

Tisch S, Rothwell JC, Limousin P, Hariz MI, Corcos DM (2007a) The physiological effects of pallidal deep brain stimulation in dystonia. IEEE Trans Neural Syst Rehabil Eng 15(2):166-172

Tisch S, Rothwell JC, Bhatia KP, Quinn N, Zrinzo L, Jahanshahi M, Ashkan K, Hariz M, Limousin P (2007b) Pallidal stimulation modifies after-effects of paired associative stimulation on motor cortex excitability in primary generalised dystonia. Exp Neurol 206:80-85

Tisch S, Zrinzo L, Limousin P, Bhatia KP, Quinn N, Ashkan K, Hariz M (2007c) Effect of electrode contact location on clinical efficacy of pallidal deep brain stimulation in primary generalised dystonia. J Neurol Neurosurg Psychiatry 78:1314-1319

Tisch S, Rothwell JC, Zrinzo L, Bhatia KP, Hariz M, Limousin P (2008) Cortical evoked potentials from pallidal stimulation in patients with primary generalized dystonia. Mov Disord 23:265-273 
Tolosa E, Montserrat L, Bayes A (1988) Blink reflex studies in focal dystonias: enhanced excitability of brainstem interneurons in cranial dystonia and spasmodic torticollis. Mov Disord 3:61-69

Touge T, Gerschlager W, Brown P, Rothwell JC (2001) Are the aftereffects of low-frequency rTMS on motor cortex excitability due to changes in the efficacy of cortical synapses? Clin Neurophysiol 112:2138-2145

Tsang EW, Hamani C, Moro E, Mazzella F, Lozano AM, Hodaie M, Yeh IJ, Chen R (2012) Movement related potentials and oscillatory activities in the human internal globus pallidus during voluntary movements. J Neurol Neurosurg Psychiatry 83:91-97

Van der Kamp W, Berardelli A, Rothwell JC, Thompson PD, Day BL, Marsden CD (1989) Rapid elbow movements in patients with torsion dystonia. J Neurol Neurosurg Psychiatry 52:1043-1049

Van Wijk BCM, Neumann WJ, Schneider GH, Sander TH, Litvak V, Kühn AA (2017) Low-beta cortico-pallidal coherence decreases during movement and correlates with overall reaction time. Neuroimage $159: 1-8$

Vidailhet M, Vercueil L, Houeto JL, Krystkowiak P, Benabid AL, Comu P, Lagrange C, Tezenas du Montcel S, Dormont D, Grand S, Blond S, Detante O, Pillon B, Ardouin C, Agid Y, Destee A, Poliak P, French Stimulation du Pallidum Interne dans la Dystonie (SPIDY) Study Group (2005) Bilateral deep-brain stimulation of the globus pallidus in primary generalized dystonia. $\mathrm{N}$ Engl J Med 352:459-467

Vitek JL, Chockkan V, Zhang JY, Kaneoke Y, Evatt M, DeLong MR, Triche S, Mewes K, Hashimoto T, Bakay RA (1999) Neuronal activity in the basal ganglia in patients with generalized dystonia and hemiballismus. Ann Neurol 46:22-35

Volkmann J, Wolters A, Kupsch A, Müller J, Kühn AA, Schneider GH, Poewe W, Hering S, Eisner W, Müller JU, Deuschl G, Pinsker MO, Skogseid IM, Roeste GK, Krause M, Tronnier V, Schnitzler A, Voges J, Nikkhah G, Vesper J, Classen J, Naumann M, Benecke R, DBS study group for dystonia (2012) Pallidal deep brain stimulation in patients with primary generalised or segmental dystonia: 5-year follow-up of a randomised trial. Lancet Neurol 11:1029-1038

Volkmann J, Mueller J, Deuschl G, Kühn AA, Krauss JK, Poewe W, Timmermann L, Falk D, Kupsch A, Kivi A, Schneider GH, Schnitzler A, Südmeyer M, Voges J, Wolters A, Wittstock M,
Müller JU, Hering S, Eisner W, Vesper J, Prokop T, Pinsker M, Schrader C, Kloss M, Kiening K, Boetzel K, Mehrkens J, Skogseid IM, Ramm-Pettersen J, Kemmler G, Bhatia KP, Vitek JL, Benecke R, DBS study group for dystonia (2014) Pallidal neurostimulation in patients with medication-refractory cervical dystonia: a randomised, sham-controlled trial. Lancet Neurol 13:875-884

Wang DD, de Hemptinne C, Miocinovic S, Qasim SE, Miller AM, Ostrem JL, Galifianakis NB, San Luciano M, Starr PA (2016) Subthalamic local field potentials in Parkinson's disease and isolated dystonia: an evaluation of potential biomarkers. Neurobiol Dis 89:213-222

Weise D, Schramm A, Stefan K, Wolters A, Reiners K, Naumann M, Classen J (2006) The two sides of associative plasticity in writer's cramp. Brain 129:2709-2721

Wolters A, Sandbrink F, Schlottmann A, Kunesch E, Stefan K, Cohen LG, Benecke R, Classen J (2003) A temporally asymmetric Hebbian rule governing plasticity in the human motor cortex. J Neurophysiol 89:2339-2345

Yianni J, Bain PG, Gregory RP, Nandi D, Joint C, Scott RB, Stein JF, Aziz TZ (2003) Postoperative progress of dystonia patients following globus pallidus intemus deep brain stimulation. Eur $\mathbf{J}$ Neurol 10:239-247

Yokochi F, Kato K, Iwamuro H, Kamiyama T, Kimura K, Yugeta A, Okiyama R, Taniguchi M, Kumada S, Ushiba J (2018) Restingstate pallidal-cortical oscillatory couplings in patients with predominant phasic and tonic dystonia. Front Neurol 9:375

Zhuang P, Li Y, Hallett M (2004) Neuronal activity in the basal ganglia and thalamus in patients with dystonia. Clin Neurophysiol 115:2542-2557

Zhu G, Geng X, Tan Z, Chen Y, Zhang R, Wang X, Aziz T, Wang S, Zhang J (2018) Characteristics of globus pallidus internus local field potentials in hyperkinetic disease. Front Neurol 9:934

Publisher's Note Springer Nature remains neutral with regard to jurisdictional claims in published maps and institutional affiliations. 